University of Nebraska - Lincoln

DigitalCommons@University of Nebraska - Lincoln

Nutrition and Health Sciences -- Faculty

Publications

Nutrition and Health Sciences, Department of

$10-2005$

\title{
Orientation to Nutrition Care Process Standards Improves Nutrition Care Documentation by Nutrition Practitioners
}

Nancy Hakel-Smith

BryanLGH Medical Center, Lincoln, NE, nhakel@bryanlgh.org

Nancy M. Lewis

University of Nebraska--Lincoln, nlewis2@unl.edu

Kent M. Eskridge

University of Nebraska-Lincoln, keskridge1@unl.edu

Follow this and additional works at: https://digitalcommons.unl.edu/nutritionfacpub

Part of the Human and Clinical Nutrition Commons, Molecular, Genetic, and Biochemical Nutrition Commons, and the Other Nutrition Commons

Hakel-Smith, Nancy; Lewis, Nancy M.; and Eskridge, Kent M., "Orientation to Nutrition Care Process Standards Improves Nutrition Care Documentation by Nutrition Practitioners" (2005). Nutrition and Health Sciences -- Faculty Publications. 19.

https://digitalcommons.unl.edu/nutritionfacpub/19

This Article is brought to you for free and open access by the Nutrition and Health Sciences, Department of at DigitalCommons@University of Nebraska - Lincoln. It has been accepted for inclusion in Nutrition and Health Sciences - Faculty Publications by an authorized administrator of DigitalCommons@University of Nebraska - Lincoln. 


\title{
Orientation to Nutrition Care Process Standards Improves Nutrition Care Documentation by Nutrition Practitioners
}

\author{
Nancy Hakel-Smith PhD, RD, ${ }^{1}$ Nancy M. Lewis PhD, RD, ${ }^{2}$ and Kent M. Eskridge $\mathrm{PhD}{ }^{3}$ \\ 1. Clinical Nutrition Services, BryanLGH Medical Center, Lincoln, NE \\ 2. Department of Nutrition and Health Sciences, University of Nebraska-Lincoln, Lincoln, NE \\ 3. Department of Statistics, University of Nebraska-Lincoln, Lincoln, NE
}

Corresponding author - Nancy Hakel-Smith

\section{Abstract}

Objective - To compare documentation of two groups of clinical nutrition practitioners for evidence of the nutrition care process.

Design - This study used a comparative descriptive design. A retrospective chart review was conducted on all nutrition documentation in closed patient records. Documentation of two groups of nutrition practitioners (institution $\mathrm{A}=$ practitioners who received initial orientation and routine reinforcement in use of nutrition care process standards; institution $\mathrm{B}=$ practitioners who received orientation in use of a further assessment and medical nutrition therapy intervention procedure) was compared for evidence of a six-step nutrition care process.

Sample/Setting - The sample consisted of randomly selected patient records $(N=60)$. A total of 15 oncology and 15 chronic renal failure patient records from each of two Midwestern tertiary-care hospitals were reviewed.

Main Outcome Measures - Outcome measures were number of nutrition care process steps documented, appropriate relationships among documented steps in the nutrition care process, and the number of complete, incomplete, and interrupted chains.

Statistical Analyses - Two-sample $t$ tests and $\chi^{2}$ analyses were used.

Results - Nutrition practitioners at institution A documented approximately three times as many nutrition care process steps per patient per chain that demonstrated appropriate relationships as did nutrition practitioners at institution B $(2.69 \pm 1.15$ and $0.80 \pm 0.62$, respectively [mean \pm standard deviation]) $(P$ $<.001)$. There were no outcome judgments related to goals documented in chains at either institution and because of this there were no completed nutrition care process chains at either institution.

Conclusions - Nutrition practitioners with orientation to nutrition care process standards documented more related nutrition care process steps than practitioners without this orientation. Providing nutrition practitioners with ongoing education and clinical experiences in use and documentation of the nutrition care process and a standardized language may be indicated to increase the number of completed nutrition care process chains and improve documentation of nutrition care and patient outcomes.
T he importance of clinical documentation in patient records has played a prominent role in the delivery and evaluation of health care for more than a century (1-13). Today, documentation of clinical services within health care systems has become increasingly significant because more detailed clinical information is required by accrediting agencies and third-party payers in their evaluation of patient care and because there is an increasing emphasis on patient outcomes (10-18). Medicine and nursing have responded to these documentation requirements by integrating the scientific method and standardized languages into their practices to document their contributions to patient care outcomes (19-29).

Clinical documentation in patient records is used as the primary source of information to evaluate patient care; therefore, clinical nutrition practitioners need to integrate the scientific method and a standardized language into nutrition practice to uniformly and completely document essential information to describe their contributions to patient outcomes. In 2003, the American Dietetic Association (ADA) adopted a nutrition care process and is developing a language for the dietetics profession; however, full implementation is expected to take approximately a decade (E. F. Myers, personal communication, April 2004) (30).

The lack of implementation of the standardized nutrition care process with standard terms for nutrition care and its outcomes has been identified as a barrier to uniform documentation of nutrition care services and to recognition in the health care community of nutrition practitioners' contributions to patient outcomes (31). Uniform and complete documentation of nutrition care and outcomes, by nutrition practitioners, is essential to (a) evaluate and coordinate care; (b) demonstrate the type, level, and complexity of nutrition care; and (c) generate new knowledge on the effectiveness and outcomes of nutrition care. 
Pioneers advancing the field of nutrition have suggested a nutrition care process based on the scientific process that guided the development of medicine and nursing. In 1985, Kight developed a standardized language for documenting nutrition problems that nutrition practitioners are responsible for identifying and treating $(32,33)$. With the introduction of nutrition diagnoses, Kight defined the nutrition care process as five steps: assess, diagnose, plan, implement, and evaluate. Years of study and clinical testing led Kight to expand the nutrition care process to nine steps (34). In 2002, Lacey and Cross presented a nutrition care process model, including nutrition diagnosis (35). For the nutrition diagnosis step they provide a common language that can be used to describe nutrition problems and develop the care plan.

In 2003, the ADA adopted a standardized nutrition care process "for implementation and dissemination to the dietetics profession and the Association for the enhancement of the practice of dietetics" (30). They defined the nutrition care process as four distinct but interrelated and connected steps, including nutrition diagnosis. All of these definitions of the nutrition care process complement the medical and nursing process and are consistent with the scientific method of problem solving.

The commonalities found in the defined nutrition care processes reflect six steps or clinical judgments that are consistent with the scientific problem-solving process (3638). Six steps or clinical judgments include: (a) deliberate collection of evidence, (b) determine diagnosis, (c) determine etiology, (d) establish goals, (e) determine and implement interventions, and (f) measure and evaluate patient outcomes (38). The six-step nutrition care process can be used as an organizing framework to standardize and direct the delivery of nutrition care and provide the basis to document the scientific approach to problem identification, treatment, and evaluation of nutrition care. The problemsolving process is a continuous series of thinking and actions with an end result (39).

The six-step nutrition care process is consistent with the nutrition care process adopted by the ADA (38). Although the ADA defines the nutrition care process as four steps and with different terms, both definitions are based on the scientific method of problem solving and require the same six judgments.

Nutrition practitioners and dietetics interns are now being educated to use a scientific problem-solving nutrition care process as a framework to guide and document nutrition practice $(32,34-37,40,41)$. Currently, knowledge about how nutrition practitioners with this orientation document the nutrition care process is not available. Furthermore, even without this orientation, what nutrition practitioners document is unknown. Information is needed to describe the content and comprehensiveness of nutrition practitioners' documentation of the nutrition care process.

The purpose of this study was to compare documentation of two groups of nutrition practitioners for evidence of the nutrition care process. Results can provide direction for development of education and clinical experiences needed by nutrition practitioners to improve documentation of nutrition care services and demonstrate their contributions to patient outcomes.

\section{Methods}

\section{Design}

This study used a comparative, descriptive design (14). A retrospective chart review was conducted on all nutrition practitioners' documentation in 60 closed patient records. Documentation of two groups of nutrition practitioners (institution $\mathrm{A}=$ practitioners who received initial orientation and routine reinforcement in use of the nutrition care process standards; institution $\mathrm{B}=$ practitioners who received orientation in use of a further assessment and medical nutrition therapy intervention procedure) was compared for evidence of a six-step nutrition care process. A content analysis instrument was used to evaluate nutrition documentation (42-48).

Since 1996, nutrition practitioners at institution A have received an initial orientation that involves two components: (a) didactic orientation and (b) experiential learning, working with an experienced practitioner, and observation and feedback by the clinical nutrition manager. The didactic orientation to the expectations is delineated in a resource orientation manual, which includes: nutrition care process standards that outline the steps to be completed for patients at nutritional risk, and a standardized diagnostic language to name and communicate nutrition problems (diagnostic categories). The manual includes readings on diagnosis and the diagnostic reasoning process, critical thinking, evidence-based practice, outcomes, and outcome indicators; the nutrition physical examination; nutrientdrug interactions; and vitamin therapy. Experiential learning is facilitated in the clinical setting with routine followup reinforcement that includes feedback during clinical rounds by the clinical nutrition manager in use and documentation of the nutrition care process standards. In addition, team meetings are used to strengthen practitioners' knowledge, application, and documentation of the scientific care process.

Since 1995, nutrition practitioners at institution B have received orientation that involves the Joint Commission on Accreditation of Healthcare Organizations nutrition assessment standards and focuses on further assessment. A procedure for nutrition further assessment and medical nutrition therapy intervention was in place. Examples of activities performed by the nutrition practitioner when performing a further assessment of patients identified at nutritional risk include: estimation of nutritional needs, anthropometric measurements and evaluations, nutritional implications of selected laboratory tests, and a physical examination for manifestations of nutrient deficiency or excess.

\section{Setting/Sample}

The setting for this study was two Midwestern, tertiarycare hospitals. Each hospital had patient services located in two facilities ranging in size from 190 to 290 beds. The sample consisted of randomly selected patient records $(N$ = 60) (49). A total of 15 oncology patient records (ie, the International Classification of Diseases, 9th revision [ICD-9] medical codes 150.0-151.9 and 152.0-153.9) and 15 chronic 


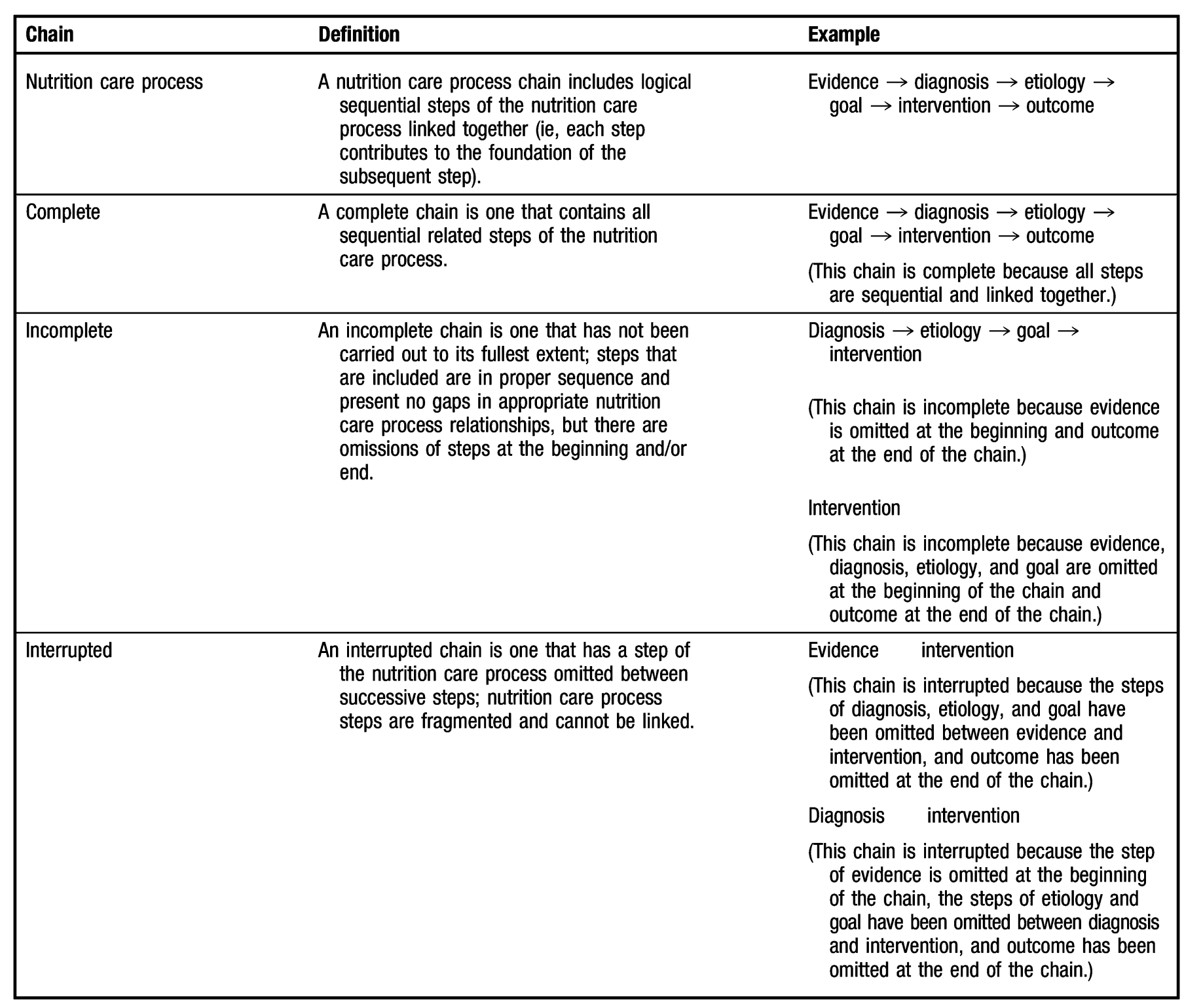

Figure 1. Definition of nutrition care process chains used in data collection.

renal failure patient records (ie, ICD-9 medical code 585.0) were randomly sampled from each institution. Medical records staff identified and retrieved patient records with these ICD-9 classification codes for patients discharged during January 2002 through April 2003. Closed records of patients 19 years of age or older who had a minimum of a 4-day hospital length of stay were used.

The institutional review boards at each of the participating hospitals and at the University of Nebraska approved the study.

\section{Evaluation Instrument}

A process evaluation instrument, coding form, and codebook were developed for this study to analyze nutrition documentation (50). The instrument was used to collect nutrition care process data. The content of the instrument was developed from the conceptual framework of the six-step nutrition care process that defines nutrition practice as a series of related activities, organized into steps to achieve identified goals. The instrument was used to identify (a) the presence or absence of the nutrition care process steps, (b) appropriate relationships between the steps of the nutrition care process, and (c) completeness of the nutrition care process chain. The nutrition care process relationships the instrument identified included evidence (the first step that initiates the sequence of the nutrition care process chain), nutrition diagnosis related to evidence, etiology related to evidence, goals related to diagnosis and etiology, interventions related to goals, and outcomes related to goals.

These relationships are defined as chains of the nutrition care process (50). For this study, three types of chains were identified: complete, incomplete, and interrupted as defined in Figure 1. 
The codebook provided explicit instructions for coding the content of nutrition documentation. The codebook with definitions for each category and explicit coding instructions enhances the reliability of the evaluation instrument (48).

A pilot study using the process evaluation instrument, the coding form, and codebook was conducted on a random sample of 10 records from the sample population. Further refinements included more explicit definitions of nutrition care process steps and changes in the codebook were made on the basis of the pilot study.

The evaluation instrument went through several stages of validity and reliability testing. Two experienced clinical registered dietitians who had education in the nutrition care process reviewed the instrument for content validity. The instrument was revised based on their comments and three nursing academicians with expertise in the nursing process verified the content validity of the revised version. Further refinements were made based on their review.

The reliability of coding by the principal investigator was established by having the principal investigator and two trained coders (an MS, RD with clinical experience and education in the nutrition care process, and a $\mathrm{PhD}$ nurse academician with expertise in the nursing process) evaluate the same five patient records. The inter-rater reliability coefficient for the three coders was 0.98 (47).

\section{Data Collection and Analysis}

All data were collected during 2003. Demographic data included patient age, sex, and length of hospital stay. Nutrition care process steps were recorded, relationships determined, and then the completeness of the nutrition care process chain was recorded on the coding form. Data collected were from all nutrition documentation in each patient record by nutrition practitioners from admission through discharge.

Means, standard deviations, and two sample $t$ tests were used to compare patient age, length of hospital stay, mean number of nutrition care steps per patient per chain, and mean number of chains documented at each institution; $x^{2}$ tests were used to compare the two institutions regarding the frequency of occurrence of relationships among documented nutrition care process steps and complete, incomplete, and interrupted chains. Level of significance was established at $P<.05$.

\section{Results}

Two renal patient records from institution A were omitted because there was no documentation by a nutrition practitioner, resulting in a total of 58 patient records used. There were a total of 66 notes coded for institution $\mathrm{A}$ and 72 notes for institution B. Eight nutrition practitioners at institution A and 10 at institution B documented the nutrition care notes that were analyzed.

Patient demographic characteristics were similar in the two institutions. The mean age of subjects in institutions A and B were $67.2 \pm 17.6$ years (mean \pm standard deviation) and $71.5 \pm 13.6$ years, respectively, and the mean hospital length of stay was $7.61 \pm 3.7$ days and $9.30 \pm 5.8$ days at institutions $\mathrm{A}$ and $\mathrm{B}$, respectively. The percentage of men and
Table 1. Comparison of mean number of nutrition care process steps $^{a}$ per patient per chain documented by nutrition practitioners at two Midwestern hospitals

\begin{tabular}{lcc}
\hline Medical diagnosis & Institution A & Institution B \\
& \multicolumn{2}{c}{ mean $\pm S D^{\mathrm{b}}$} \\
\hline Oncology & $2.99 \pm 0.63^{* * *}$ & $0.94 \pm 0.74$ \\
Renal & $2.38 \pm 1.46^{* * *}$ & $0.66 \pm 0.46$ \\
Overall mean & $2.69 \pm 1.15^{* * *}$ & $0.80 \pm 0.62$ \\
\hline
\end{tabular}

a. To be included each nutrition care process step needed to show the appropriate relationship.

b. SD = standard deviation.

${ }^{* * *} P<.001$, based on a two-sample $t$ test.

women were the same at the two institutions ( $43 \%$ women and $57 \%$ men).

\section{Nutrition Care Process Steps}

Mean number of nutrition care process steps per patient per chain documented in nutrition care process chains for oncology and renal patients at the two institutions are presented in Table 1. Nutrition practitioners at institution A documented approximately three times as many nutrition care process steps per patient per chain that demonstrated appropriate relationships as nutrition practitioners at institution B.

\section{Relationships of Nutrition Care Process Steps}

Figure 2 shows the percentage of nutrition care process chains with related nutrition care process steps documented by nutrition practitioners in patient records at institutions $\mathrm{A}$ and B. Evidence initiated the nutrition care process chain in approximately one third of the chains at both institutions. Nutrition diagnoses and etiologies were readily identified and related to evidence in more than half of the chains (73\% and $60 \%$, respectively) at institution A. At institution $B$, nutrition diagnoses were identified and related to evidence in approximately one third $(34 \%)$ of the chains; however, etiologies related to evidence were absent in chains.

Goals related to diagnoses and etiologies were identified in more than $60 \%$ of the nutrition care process chains at institution $\mathrm{A}$ and interventions related to goals were identified in more than $80 \%$ of the chains at this institution. Goals related to diagnoses and etiologies were $a b-$ sent in records at institution B; however, interventions related to goals were present in almost $30 \%$ of the records. There were no outcome judgments related to goals documented in chains at either institution, and because of this there were no completed nutrition care process chains at either institution.

Overall, nutrition practitioners at institution A documented four steps that demonstrated appropriate relationships in nutrition care process chains more frequently $(P<$ .001) than nutrition practitioners at institution B: diagnoses and etiologies related to evidence, goals related to diagnosis and etiologies, and interventions related to goals. 


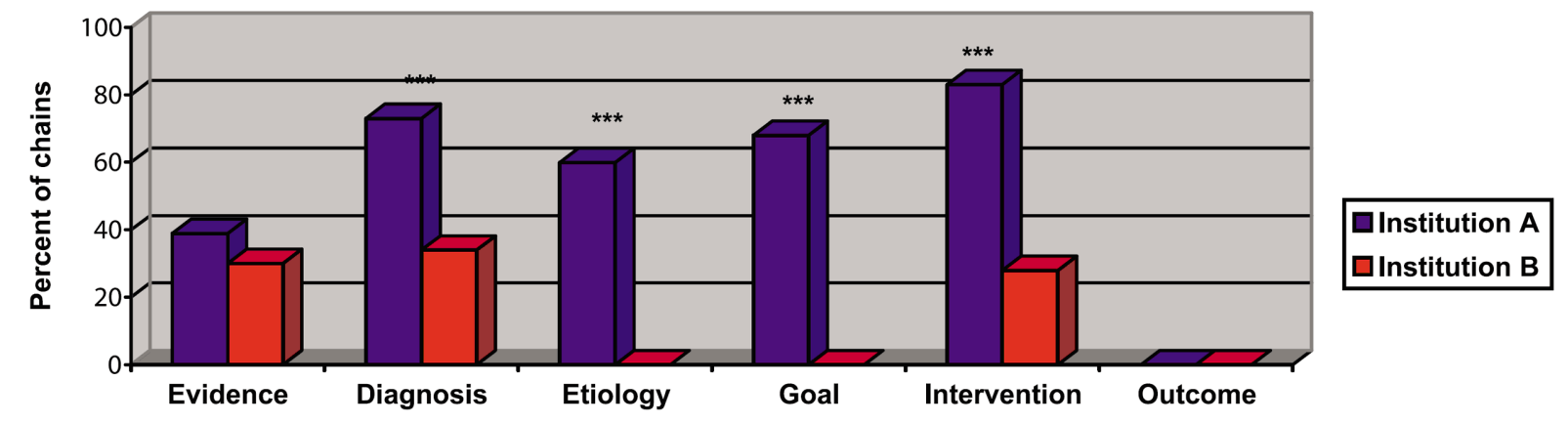

Figure 2. Percent of nutrition care process chains with related nutrition care process steps documented for oncology and renal patients at two medical institutions. ${ }^{* *} P<.0001$. Based on $x^{2}$ tests.

\section{Discussion}

This study compared documentation for use of the nutrition care process by two groups of nutrition practitioners; one group had previously received initial orientation and routine follow-up reinforcement in use of nutrition care process standards (institution A), the other group received orientation in a further assessment and medical nutrition therapy intervention procedure (institution B). The nutrition care documented in the patient records differed between the two institutions. Nutrition practitioners at institution A documented more related nutrition care process steps than nutrition practitioners at institution B; however, there were deficiencies in documentation of the nutrition care process by both groups of practitioners. This may support the need for education in use and documentation of the nutrition care process with an emphasis on outcomes to improve documentation of nutrition care services.

\section{Evidence, Diagnosis, and Etiology}

Evidence, diagnosis, and etiology represent the problem-identification phase of the nutrition care process (38). Documentation of evidence was similar in the two institutions. This finding supports the literature that suggests nutrition practitioners are educated about the importance of gathering evidence (51-53). The diagnostic reasoning process begins with gathering and documenting evidence for the purpose of determining the patient's nutrition problem and its etiology; therefore, the accuracy of the diagnosis depends on the accuracy of the evidence gathered.

Identification of the patient's nutrition diagnosis and its etiology directs the focus of the remaining steps of the nutrition care process; consequently, nutrition practitioners require skills not only in gathering and documenting relevant data, but also in interpreting the data into a diagnosis and its etiology. Nutrition practitioners' evidence-gathering skills provide a sound foundation for ongoing education about the diagnostic reasoning process and interpretation of gathered evidence into a nutrition diagnosis and etiology $(29,54-56)$. More frequent documentation of nutrition diagnoses and etiologies related to evidence at institution A may have resulted from the orientation these practitioners received. They are provided with and taught to use a standardized diagnostic language for making and documenting both nutrition diagnoses and etiologies.
Nutrition practitioners at institution B documented a nutrition diagnosis related to evidence in approximately one third of the chains. The nutrition diagnoses documented by practitioners at institution B were typically judgments regarding the patients' nutritional risk status or use of medical diagnosis. Although nutrition practitioners at institution B did not include formal use of standard terms for nutrition diagnoses, some of the practitioners seemed to interpret nutritional problems from a dieteticspecific model. When nutrition practitioners at institution $\mathrm{B}$ interpreted data into a diagnosis they did not complete the diagnostic reasoning process by interpreting data into an etiology or cause of the problem. Determining an etiology is an important step in the diagnostic reasoning process because it becomes the focus for determining nutrition interventions needed to attain stated goals and to resolve or progress toward resolution of the problem (57).

When a standardized language is used to document the nutrition diagnosis and its etiology, the nutrition problem and what is causing it can be communicated to other members of the health care team and the focus of nutrition care becomes clear. Use of a standardized language for nutrition diagnosis across institutions can lead to uniform documentation and description of nutrition problems and make it possible to gather outcomes data for evidence of the effectiveness of nutrition practitioners' interventions. While practitioners at institution A demonstrated application of the problem-identification phase of the nutrition care process, at institution B two steps of the problem-identification phase were used.

\section{Goals, Interventions, and Outcome Evaluation}

Goals, interventions, and outcome evaluation represent the problem-solving phase of the nutrition care process (38). Nutrition practitioners at institution A demonstrated a high level of competency in documenting goals related to diagnoses and etiologies and interventions related to goals. It seems that the orientation provided to nutrition practitioners at institution A resulted in understanding the importance of establishing goals related to the diagnosis and etiology. Establishing goals is an important judgment because goals structure the problem-solving task by defining the boundaries of the problem to be solved, direct the determination and implementation of nutrition interventions needed to achieve the goals, and provide the crite- 
ria to evaluate the progress toward resolution of the diagnosis and the effectiveness of nutrition interventions. At institution B there was not a clear relationship between documented patient goals and nutrition diagnoses and etiologies.

Documenting interventions related to goals at institution A was the step in the process that occurred with the most frequency. It was clear that the nutrition interventions were prescribed to achieve stated goals and resolve the nutrition problem. However, at institution B this relationship was not as evident.

There were no outcomes related to goal achievement documented at either institution. This meant there were no completed chains identified. This finding supports the low documentation of outcome evaluation by nutrition practitioners previously reported by others $(31,52,53)$. Documenting judgments about whether the outcome(s) was achieved is essential to communicate patient's progress toward attaining established goals and the effectiveness of the practitioner's intervention(s). Effectiveness research of nutrition care will only be possible through uniform and complete documentation linking the nutrition care process or the dietetics professional's clinical decisions with patient outcomes. The lack of documentation of patient outcomes at both institutions makes it impossible to evaluate the effectiveness of nutrition interventions.

\section{Comprehensive Documentation of the Nutrition Care Process}

Documentation of the nutrition care process included incomplete and had interrupted chains at both institutions. This indicates that the scientific logic used by practitioners to identify and solve problems was partially evident in documentation. These data are consistent with similar results reported in nursing studies (58-63). Blewitt and Jones reported that inconsistent use and documentation of the critical data elements of nursing diagnoses, goals, and associated interventions made it impossible to establish a clear link between nursing activities and patient outcomes (58).

Comprehensive documentation of the nutrition care process chain or the identification, treatment, and resolution of nutrition problems is essential to provide evidence of nutrition practitioners' contribution to patient outcomes. When the systematic steps of the nutrition care process or the nutrition practitioner's clinical judgments are consistently defined and documented with standardized terms, this information can be collected, compared, and aggregated, and therefore used to identify the most effective treatments. In summary, clinical documentation in patient records is used as the primary source of information by multiple users to evaluate patient care. Therefore, nutrition practitioners need to uniformly and completely document essential information to communicate their judgments about patients' nutrition problems to direct interventions and optimize outcomes. Providing ongoing education in use of the scientific approach of the nutrition care process and a standardized language to uniformly and comprehen- sively document nutrition care services may be indicated to evaluate the effectiveness of nutrition care.

\section{Potential Limitations}

The following are three potential limitations of the study:

1. We cannot say with certainty that the orientation and routine follow-up reinforcement of nutrition practitioners in the nutrition care process at institution A was responsible for the improved documentation. There were other differences, such as the different documentation formats between the two institutions, that could have contributed to the results.

2. The study examined documentation of nutrition care; there could have been care provided that was not documented.

3. The two institutions in the study were located in the midwestern United States. If the study were conducted in different institutions and other parts of the country, different results may have been obtained.

Suggested follow-up research to this project includes: inclusion of a qualitative approach that incorporates observation and a one-to-one personal interview with nutrition practitioners; inclusion of a measure of nutrition practitioners' diagnostic reasoning skills; examination of the implications of incomplete and interrupted nutrition care process chains for patient outcomes, continuity and coordination of care between facilities, and reimbursement; and replication of this study with a larger and more diverse sample.

\section{Conclusions}

Clinical nutrition practitioners should use a viable nutrition care process as a framework to organize, direct, and link patient nutrition problems with nutrition interventions and patient outcomes as well as to comprehensively document their contributions to patient outcomes.

Clinical nutrition practitioners should use a standardized language for nutrition diagnoses, interventions, and outcomes to uniformly document their judgments about nutrition problems, their treatment, and resulting patient outcomes. This would provide information that could be collected, aggregated, and compared, which would make it possible to generate a new body of knowledge on the effectiveness and outcomes of nutrition care. Patients will benefit from the systematic documentation, collection, and use of this information.

To fully integrate the nutrition care process and standardized language into clinical nutrition practice, nutrition practitioners may need to be provided with ongoing education and clinical experiences in both the use and documentation of the scientific approach of the nutrition care process, with an emphasis on patient outcomes.

The most important education for nutrition practitioners may be nutrition diagnosis and the diagnostic reasoning process because of its critical link in directing the remaining steps of the nutrition care process. 
Acknowledgments - The authors thank the administrators at the hospitals who supported this research. This publication is a contribution of the University of Nebraska Agricultural Research Division, Lincoln, NE 68583 (Research Bulletin No. 14611). The research was supported in part by funds provided through the Hatch Act.

\section{References}

1 F. Nightingale, Notes on Nursing: What It Is, and What It Is Not (Facsimile edition), Harrison \& Sons, London, England (1859) Reproduced: Philadelphia, PA: Lippincott; 1946.

2 N. H. Ewing, The value of the nurse's clinical record, Am J Nurs 25 (1925), pp. 456-462.

3 T. R. Ponton, Nomenclature of Diseases and Operations and Manual of the Medical Record (2nd ed.), Physicians' Record Company, Chicago, IL (1928).

4 M. T. MacEachern, Nurses' records, Am J Nurs 28 (1928), p. 12.

5 N. H. Ewing, Introduction to clinical charting, Am J Nurs 31 (1931), pp. 169-173.

6 N. H. Ewing, The legal aspects of clinical records, Am J Nurs 31 (1931), pp. 1407-1410.

7 F. Nightingale In: C. B. Schuyler, Editor, Notes on Nursing: What it is, and what it is not (Commemorative Edition), Lippincott, Philadelphia, PA (1992).

8 E. K. Huffman, Medical Record Management (6th ed.), Physicians' Record Company, Berwyn, IL (1972).

9 F. T. Fischbach, Documenting Care: Communication, the Nursing Process and Documentation Standards, FA Davis Company, Philadelphia, PA (1991).

10 Joint Commission for Accreditation of Healthcare Organizations. Comprehensive Accreditation Manual for Hospitals. Oakbrook Terrace, IL: 2004.

11 Committee on Quality Health Care in America, Crossing the Quality Chasm: A New Health System for the 21st Century, National Academy Press, Washington, DC (2001).

12 R. S. Dick, E. B. Steen and D. E. Detmer, The ComputerBased Patient Record: An Essential Technology for Health Care, National Academy Press, Washington, DC (1997).

13 K. N. Lohr, Medicare: A Strategy for Quality Assurance, National Academy Press, Washington, DC (1990).

14 N. Burns and S. K. Grove, The Practice of Nursing Research: Conduct, Critique, and Utilization (4th ed.), Saunders Company, Philadelphia, PA (2001).

15 D. A. August, Creation of a specialized nutrition support outcomes research consortium: If not now, when?, J Parenter Enteral Nutr 20 (1996), pp. 394-400.

16 C. D. Mullins, R. Baldwin and E. M. Perfetto, What are outcomes?, J Am Pharm Assoc NS36 (1996), pp. 39-49.

17 C. G. Chute, S. P. Cohn and J. R. Campbell, A framework for comprehensive health terminology systems in the United States: Development guidelines, criteria for selection and public policy implications, J Am Med Inform Assoc 5 (1998), pp. 503-510.

18 A. R. Tarlov, J. E. Ware, S. Greenfield, E. C. Nelson, E. Perrin and M. Zubkoff, The medical outcomes study: An ap- plication of methods for monitoring the results of medical care, JAMA 262 (1989), pp. 925-930.

19 L. S. King, Medicine seeks to be 'scientific,' JAMA 249 (1983), pp. 2475-2479.

20 The scientific physician, Boston Med Surg J 142 (1900), pp. 701-702.

21 A. R. Feinstein, ICD, POR, and DRG: Unsolved scientific problems in the nosology of clinical medicine, Arch Intern Med 148 (1988), pp. 2269-2274.

22 A. C. Hart, B. Ford, C. A. Hopkins, R. M. Magnani and K. Schmidt, International Classification of Diseases 9th revision: Clinical Modification for Hospitals, Ingenix, Inc, Reston, VA (2004).

23 K. Holden, C. Hopkins and K. Kachur, Current Procedural Terminology, Ingenix, Inc, Salt Lake City, UT (2004).

24 Systematized Nomenclature of Medicine (SNOMED); 2000 to 2003, College of American Pathologists. Accessed November 5, 2004 from http://snomed. com

25 H. Yura and M. B. Walsh, The Nursing Process: Assessing, Planning, Implementing, Evaluating (5th ed.), Appleton and Lange, Norwalk, CT (1988).

26 Sparks, S. Ralph, M. Craft-Rosenberg, T. H. Herdman and M. A. Lavin, Nursing Diagnoses: Definitions \& Classification 2003-2004, NANDA International, Philadelphia, PA (2003).

27 J. McCloskey Dochterman and G. M. Bulechek, Iowa Intervention Project: Nursing Interventions Classification (NIC), Mosby, St Louis, MO (2004).

28 S. Moorehead, M. Johnson and M. Maas, Nursing Outcomes Classification (NOC) (3rd ed.), Mosby, St Louis, MO (2004).

29 M. Gordon, Nursing Diagnosis: Process and Application, Mosby, St Louis, MO (1994).

30 K. Lacey and E. Pritchett, Nutrition care process and model: ADA adopts road map to quality care and outcomes management, J Am Diet Assoc 103 (2003), pp. 1061-1072.

31 P. Splett and E. F. Myers, A proposed model for effective nutrition care, J Am Diet Assoc 101 (2001), pp. 357-363.

32 M. A. Kight, Working with diagnosis related groups (DRGs): Diagnosis in the practice of selected health-medical team members, Nutrition Support Services 5 (1985), pp. 39-46.

33 M. A. Kight, Notice of change of nutritional diagnostic classification system title, Diagnostic Nutrition Network 12 (2003), p. 7.

$34 \mathrm{~K}$. Sandrick, Is nutritional diagnosing a critical step in the nutrition care process?, J Am Diet Assoc 102 (2002), pp. 427-431.

35 K. Lacey and N. Cross, A problem-based nutrition care model that is diagnostic driven and allows for monitoring and managing outcomes, J Am Diet Assoc 102 (2002), pp. 578-589.

36 N. M. Lewis, N. Hakel-Smith and M. A. Kight, Linking the nutritional care process with outcomes research (2000) Proceedings, XIII International Congress of Dietetics. Edinburgh, UK.

37 N. Hakel-Smith, M. A. Kight and N. M. Lewis, Nutrition practice languages, classification systems and minimum 
data sets: Essential elements for the successful linkage of clinical nutrition practice with outcomes research (1999) Proceedings, The American Dietetic Association National Meeting. Atlanta, GA.

38 N. Hakel-Smith and N. M. Lewis, A standardized nutrition care process and language are essential components of a conceptual model to guide and document nutrition care and patient outcomes, J Am Diet Assoc 104 (2004), pp. 1878-1884.

39 M. G. Rubenfeld and B. K. Scheffer, Critical Thinking in Nursing: An Interactive Approach (2nd ed.), Lippincott, Philadelphia, PA (1999).

40 N. Hakel-Smith, A Network professional brief on implementing the new JCAHO standards, Diagnostic Nutrition Network 4 (1995), p. 7.

41 N. Hakel-Smith, A Network professional brief on a "Class in the Round," Diagnostic Nutrition Network 6 (1997), pp. 6-7.

42 K. A. Neuendorf, The Content Analysis Guidebook, Sage Publications, Thousand Oaks, CA (2002).

43 R. P. Weber, Basic Content Analysis (2nd ed.), Sage Publications, Newburg Park, CA (1990).

44 F. N. Kerlinger, Foundations of Behavioral Research (3rd ed.), Holt, Rinehart and Winston, Inc, Fort Worth, TX (1986).

45 K. Krippendorf, Content Analysis: An Introduction to Its Methodology, Sage Publications, Newbury Park, CA (1980).

46 K. D. Bailey, Methods of Social Research, The Free Press, A Division of Macmillan Publishing Co, Inc, New York, NY (1978).

47 O. R. Holsti, Content Analysis for the Social Sciences and Humanities, Addison-Wesley Publishing Company, Reading, MA (1969).

48 B. Berelson, Content Analysis. In: G. Lindzey, Editor, Handbook of Social Psychology, Addison-Wesley Publishing Company, Inc, Cambridge, MA (1954).

49 W. W. Daniel, Biostatistics: A Foundation for Analysis in the Health Sciences (6th ed.), John Wiley \& Sons, Inc, New York, NY (1995).

50 J. A. Baumgart, Instrument Development for Quality Evaluation of Public Health Nursing Records, University of Illinois, Chicago, IL (1975) Thesis.
51 G. E. Gates, Clinical reasoning: An essential component of dietetic practice, Top Clin Nutr 7 (1992), pp. 74-80.

52 M. B. Foltz, M. R. Schiller and A. S. Ryan, Nutrition screening and assessment: Current practices and dietitians' leadership roles, J Am Diet Assoc 93 (1993), pp. 1388-1395.

53 C. Biesemeier and C. S. Chima, Computerized patient record: Are we prepared for our future practice?, J Am Diet Assoc 97 (1997), pp. 1099-1104.

54 J. M. Wilkinson, Nursing Process: A Critical Thinking Approach (2nd ed.), Addison-Wesley Nursing, Menlo Park, CA (1996).

55 R. Alfaro-LeFevre, Applying Nursing Process: A tool for critical thinking (6th ed.), Lippincott, Philadelphia, PA (2006) In press.

56 M. E. Doenges, M. F. Moorhouse and J. T. Burley, Application of Nursing Process and Nursing Diagnosis: An Interactive Text for Diagnostic Reasoning (4th ed.), FA Davis Company, Philadelphia, PA (2003).

57 M. O. Mundinger and G. D. Jauron, Developing a nursing diagnosis, Nurs Outlook 23 (1975), pp. 94-98.

58 D. K. Blewitt and K. R. Jones, Using elements of the nursing minimum data set for determining outcomes, JONA 26 (1996), pp. 48-56.

59 M. Ehnfors and B. Smedby, Nursing care as documented in patient records, Scand J Caring Sci 7 (1993), pp. 209-220.

60 R. Suhayda and M. J. Kim, Documentation of Nursing Process in Critical Care. In: M. J. Kim, G. K. McFarland and A. M. McLane, Editors, Classification of Nursing Diagnoses: Proceedings of the Fifth National Conference, Mosby, St Louis, MO (1984).

61 M. R. Bleich, A Study of Nursing Documentation Systems for Recorded Evidence of the Nursing Process, Master's thesis, University of Minnesota, Minneapolis (1987).

62 M. J. Sullivan, Reflections of the nursing process in two methods of recording nurses' notes. In: H. H. Werely and M. R. Grier, eds., Nursing Information Systems, Springer Publishing Co, New York, NY (1981).

63 A. Ehrenberg, M. Ehnfors and I. Thorell-Ekstrand, Nursing documentation in patient records: Experience of the use of the VIPS model, J Adv Nurs 24 (1996), pp. 853-867. 